\title{
La educación militar en tiempos de guerra. Los orígenes del Colegio Militar de la Nación (Argentina, 1869-1880)*
}

\author{
Lucas Codesido ${ }^{* *}$ \\ Recibido: 22 de agosto de 2020 \\ Dictaminado: 22 de diciembre de 2020 \\ Aceptado: 12 de enero de 2021
}

\section{REsumen}

El artículo analiza la génesis del Colegio Militar de la Nación (Argentina) en sus primeros años de existencia, vinculando su trayectoria con una serie de políticas específicas tendientes a la centralización del poder militar emprendidas durante la presidencia de Sarmiento. Se articula el empeño por controlar a la Guardia Nacional junto con la apuesta por convertir al Ejército de Línea en la plataforma escogida para la profesionalización de las fuerzas militares nacionales. Abordar la educación militar en la década de 1870 se vincula con la subordinación de las fuerzas armadas al Estado nacional, un atributo que se manifiesta en el control del ejército por parte de la autoridad presidencial y emerge como rasgo distintivo del futuro oficial formado en el Colegio Militar.

* $\quad$ Este artículo forma parte de un trabajo mayor desarrollado como tesis de doctorado: “Armar al Estado, construir la Nación. La nacionalización de las fuerzas armadas en la Argentina y su vinculación con el proceso de construcción del Estado nacional". Tesis de Doctor en Historia. La Plata. Fahce/unLP, 2016.

** Departamento de Derecho y Ciencia Política, Universidad Nacional de La Matanza, San Justo, Buenos Aires, Argentina. Correo electrónico: 1codesid@ungs.edu.ar. ORCID: https://orcid.org/0000-0003-3309-144X 
Hemos estudiado la puesta en marcha del colegio en sus primeros años de existencia y examinado las formas en que la disputa político-militar se colaba en sus aulas modificando algunos de los protocolos ideados para separar al Ejército de las contiendas partidarias. Este estudio identifica esos componentes y expone sus trayectorias dentro de las dinámicas, prácticas y proyectos que apuntan a lograr el monopolio de la fuerza militar y constituyen una parte central del proceso de consolidación del Estado nacional en la Argentina.

Palabras clave: Ejército, Colegio Militar de la Nación, Sarmiento, fuerzas armadas.

\section{The military education in times of war. The origins of the Military College of the Nation (Argentina, 1869-1880)}

\section{Abstract}

The article analyzes the genesis of the National military college (Argentina) in its first years of existence, linking its trajectory with a series of specific policies aimed at the centralization of military power undertaken during the Sarmiento presidency. The effort to gain control the National Guard is linked to the commitment to turn the Army of the Line into the chosen platform for the professionalization of the national military forces. Military education is linked to the subordination of the armed forces to the national State and is expressed in the control of the army by the presidential authority. This attribute emerges as a distinctive feature of the future officer trained in the Military College. We have studied the start-up of the school in its first years of existence and examined the ways in which the political-military dispute crept into its classrooms by modifying some of the protocols devised to separate the Army from partisan fight. This study identifies these components and exposes their trajectories within the dynamics, practices and projects that aim to achieve the monopoly of military force and constitute a central part of the consolidation process of the national State in Argentina.

Key words: Army, National Military College, Sarmiento, armed forces.

\section{INTRODUCCIÓN}

El arribo de Domingo F. Sarmiento a la presidencia (1868-1874) tuvo una característica distintiva que le confirió un sello personal a su gobierno. $\mathrm{Su}$ triunfo representaba la victoria de un candidato sin partido propio, lo cual 
implicaba la llegada al gobierno de alguien ajeno a la desgastante lucha diaria de las facciones y que había sido colocado para elevarse sobre las aspiraciones e intereses de estos grupos. Sarmiento retornaba de su misión diplomática en los Estados Unidos y se presentaba como alguien que no iba a distinguir entre amigos y enemigos a la hora de aplicar la ley, proponiendo una conducción y liderazgo que no estarían sujetos a favores personales. ${ }^{1} \mathrm{Al}$ acceder a la presidencia, Sarmiento propone establecer un principio de autoridad que pretendía ejercer, según sus propias definiciones, "la función ejecutiva en la mayor medida que la Constitución tolerase", y en ese sentido, estaba convencido de que el monopolio del uso de todas las fuerzas militares era una potestad exclusiva del Poder Ejecutivo, inherente a su rol de Comando en Jefe del Ejército. Este atributo fue ejercido de forma efectiva y no solamente nominal por el propio Sarmiento en distintas situaciones en donde la intervención del Ejecutivo se apoyaba en la consigna de fomentar la institucionalidad en todos los niveles del Estado. ${ }^{2}$ A la hora de defender la Constitución, Sarmiento no dudará en sostener que:

...La ley militar está al frente de la Constitución de los Estados Unidos y de la nuestra también. Ante ella enmudecen las garantías individuales proclamadas por el pueblo libre. El ciudadano norteamericano mismo desaparece, desde que en la Constitución se le muestra el tambor pronto a sonar (...) No hay, pues, justicia federal para el que lleva en las manos el arma que le ha confiado el Estado, la que toma contra él. Los nacidos en la República Argentina son miembros de la Guardia Nacional, estén enrolados o no, entiéndanlo bien; y desde que un argentino lleva un arma y un paquete de cartuchos, está sujeto a las terribles leyes militares que precaven a la sociedad de que esos cartuchos vayan a la boca del fusil sin orden del jefe de Estado. ${ }^{3}$

1 En términos facciosos, al momento de su llegada al poder hay un federalismo representado por la figura de Urquiza, un mitrismo y un alsinismo, encarnados en Mitre y Alsina respectivamente, pero no un sarmientismo.

2 Aunque este fuerte acento puesto en el respeto por la constitucionalidad no le impedirá recurrir a otros marcos legales para completar los vacíos que el texto constitucional deja abiertos y sobre los que todavía no hay un marco regulatorio acorde con los tiempos republicanos. En este sentido, respecto de las fuerzas armadas, la inexistencia de un Código Militar, que recién será sancionado en 1895, hace que Sarmiento no dude en postular la vigencia de las Ordenanzas Militares de Carlos III (1768). Aplicando el rigor de la antigua legislación monárquica en situaciones como la aprobación de la pena capital a los desertores del ejército o bien, para juzgar a los acusados de delitos de rebelión que el gobierno considera sujetos a jurisdicción militar. Esta política será llevada a cabo desde una posición que sostiene la defensa y el funcionamiento de la autoridad legal ante lo que el gobierno y sus agentes considerarán situaciones que ponen en peligro la vigencia de las instituciones constitucionales. Codesido, Lucas, "Zacarías segura, "Salteador y Montonero", pp. 223-248.

3 Artículo publicado en el diario El Nacional, el 13 de abril de 1869, escrito en respuesta al editorial "Jurisprudencia de sangre" aparecido en La Nación, sin firma de autor, pero 
Con estas consignas Sarmiento se ocupó de definir el rol del ejército y de la Guardia Nacional. Sostuvo fuertes disputas con los gobiernos provinciales en relación con la autoridad y potestad sobre las fuerzas militares de origen local, ${ }^{4}$ que el presidente reclamaba para la nación. Aquellas disputas se debían en parte a que las definiciones acerca de las incumbencias militares que la Constitución Nacional reservaba para la Guardia Nacional estaban expuestas con una cierta ambigüedad que permitía algunas excepcionalidades, quedando la potestad sobre la GN sujeta a las diversas interpretaciones surgidas de las conveniencias del gobierno central o de los mandatarios provinciales. ${ }^{5}$

En esas querellas sobre la potestad y el control de la Guardia Nacional también hizo su aparición la justicia civil expresada en los tribunales federales de justicia dependientes de la recientemente creada Corte Suprema. Éstos tuvieron un importante desempeño en diversos conflictos relacionados con la disputa de atribuciones entre la justicia civil y los tribunales militares dependientes del Poder Ejecutivo. ${ }^{6}$ La tarea de centralizar el poder militar requería políticas

aparentemente escrito por Mitre a raíz de la condena a muerte del ciudadano Zacarías Segura por parte de un consejo de guerra levantado por Arredondo y defendido luego por Sarmiento. Sarmiento, Obras Completas, pp. 117.

4 "Las poblaciones nuevas en esta y la otra América se armaron desde el primer día de su existencia para defenderse, y solo cuando se constituyeron en naciones, hicieron de esta defensa local un sistema de defensa común, llamándole Guardia Nacional. El ejército regular puede suplirla o exonerarla; pero toda vez que aquel no esté en proporción con la necesidad, la universalidad de los ciudadanos constituye el Ejército Nacional, llámese milicia, Landwehr o reserva. Toda limitación, pues, que se ponga al poder nacional militar sobre el uso de la Guardia Nacional, es suicidar la Nación, y hacer nacer por fuerza lo que con tantos sacrificios destruimos o neutralizamos entre todos, a saber: las milicias, que con Ramírez y Quiroga sublevaron el país y mantuvieron la guerra constante en las provincias; las de Buenos Aires comandadas por el general don Juan Manuel de Rosas durante veintiséis años, y las veinte mil lanzas de Entre Ríos a las órdenes del capitán general Urquiza. La guerra civil de cincuenta años fue solo la antigua milicia localizada bajo un caudillo". Palabras de Sarmiento en el Mensaje de apertura del Congreso en mayo de 1872, ibid., p. 155.

5 Macías, Flavia, "Las fuerzas militares entre la provincia y la nación (1868-1874). La participación en la Guardia Nacional expresaba el principio de la ciudadanía armada y algunos significados asociados con los valores republicanos que diferenciaban a los milicianos-ciudadanos de los soldados del Ejército. Sobre este tema véase Sabato, "Resistir la imposición: revolución, ciudadanía y república en la Argentina de 1880", pp. 159-182 y Macías, "El deber de enrolarse y el derecho a votar. Reflexiones en torno a la ciudadanía armada y el sufragio en argentina, 1863-1877”, pp. 233-258. Canciani, "Las Guardias Nacionales en Argentina durante la organización nacional: balance y perspectivas historiográficas", pp. 1-12.

6 Zimmermann, "En tiempos de rebelión. La justicia federal frente a los levantamientos provinciales, 1860-1880", pp. 245-274. El caso "Segura” fue emblemático en este sentido, produjo polémica y debates en la Cámara de Senadores y la prensa en junio de 1869, luego de la ejecución de un ciudadano condenado por un tribunal militar. Codesido, "Zacarías segura, Salteador y Montonero", pp. 223-248. También: Sillitti, Nicolás, "El levantamiento armado 
específicas tendientes a conseguir la institucionalización y modernización de las fuerzas armadas. En ese sentido, reivindicar la incumbencia de la justicia militar por sobre la justicia civil implicaba un mayor control por parte del presidente y comandante en jefe, a quien responden directamente los tribunales de guerra. Por otra parte, el control de la Guardia Nacional impulsado por Sarmiento sería un importante paso hacia la consolidación de un nuevo orden político que afirmaría la transferencia de poder desde la periferia hacia el centro. El segundo paso será emplazar al Ejército de Línea como la base militar de aquella organización, de modo que la profesionalización de esta fuerza y la estructuración de sus servicios serán el centro de las preocupaciones de Sarmiento en materia militar.

En esta investigación se comprende que las normas, prácticas y acciones políticas orientadas a conducir la autoridad hacia el poder central no surgen de una estricta penetración del Estado nacional sobre la sociedad, sino más bien, de una interrelación entre los poderes provinciales y los nacionales. ${ }^{7}$ El Estado nacional se edifica sobre otras formas de autoridad preexistentes y en este estudio se propone abordar la faz militar de esta perspectiva. ${ }^{8}$ Los proyectos de renovación de las estructuras militares, expresados por la Ley de Reclutamiento (1872) y la profesionalización del cuadro de oficiales del Ejército, se asocian

de 1905. Estado, Ejército y delito político en la Argentina a comienzos del siglo xx"; Macías y Navajas, "De los comicios al campo de batalla (1874)", pp. 159-180.

7 Como ha señalado Oscar Oszlak, la conformación del Estado implicó un proceso de “expropiación social" en el cual la nueva entidad nacional en construcción fue apoderándose de un conjunto de atribuciones y ámbitos de actuación que eran propios de otras instituciones de la sociedad civil. Oszlak, La formación del Estado argentino, pp. 15-43. En los últimos años, este enfoque propuesto por Oszlak ha sido enriquecido y mejorado al ponerse a prueba en la investigación empírica en los diversos ámbitos provinciales. Se ha propuesto que las normas, las prácticas y acciones políticas orientadas a conducir la autoridad hacia el poder central no surgen de una estricta penetración del Estado nacional sobre la sociedad sino más bien, de una interrelación entre los poderes provinciales y los nacionales. Bragoni y Míguez, Un nuevo orden político. Provincias y Estado Nacional, 1852-1880, "Introducción”. A su vez la opción por el modelo de Estado centralizado convivió en tensión con otra de características descentralizantes, con foco en los poderes provinciales. Macías, "Orden y violencia política. Argentina, 1870-1880”, pp. 227-240. Sabato, Buenos Aires en armas. La revolución de 1880, pp. 298-301. Sabato, "Hacer política en tiempos de república", pp. 19-38.

8 Tal como ha señalado oportunamente Juan Carlos Garavaglia, la organización "nacional" de las fuerzas militares no se inicia con la unificación llevada a cabo por el mitrismo luego de la Batalla de Pavón (1861), ni en la década de 1870 con Sarmiento en la presidencia. Es un proceso que tiene sus bases en los esfuerzos de la Confederación Argentina, durante la década de 1850, para "construir un ejército verdaderamente nacional". Garavaglia, "Fuerzas de Guerra y construcción estatal: de la Confederación a la Nación Argentina (1856-1865)", pp. 440-442. Véase además: Lanteri, Ana Laura, "(Inter)acciones para un nuevo orden nacional. La experiencia política de San Juan a partir de la Circunscripción Militar del Oeste y el Congreso durante la "Confederación" (1855-1858)", pp. 1-21. 
con el proceso de centralización, que involucran una redefinición de las relaciones entre el Estado nacional y las provincias. ${ }^{9}$ A su vez, la formación académica de los oficiales del Ejército de Línea iniciada en la década de 1870, expresada en la creación del Colegio Militar de la Nación, se concibe para fortalecer las relaciones de mando y obediencia entre el poder central y los jefes del Ejército. En este sentido, el abordaje de la educación militar en la década de 1870 se vincula con la subordinación de las fuerzas armadas al Estado nacional. Como veremos en las líneas que siguen, el control del ejército por parte de la autoridad presidencial será el rasgo distintivo del futuro oficial formado en el Colegio Militar. Este trabajo examina esos elementos y propone trazar sus trayectorias en el marco de las dinámicas, proyectos y concreciones que apuntan a lograr el monopolio de la fuerza militar por parte del Estado nacional y constituyen una parte central del proceso de consolidación de esta entidad en la Argentina. ${ }^{10}$

Hacemos aquí una mención al recorrido del trabajo realizado a partir del acceso a diversas fuentes y repositorios. En el Servicio Histórico del Estado Mayor General del Ejército (EMGE) y Archivo General del Ejército (AGE) existe una gran cantidad de documentación oficial de las actividades del Ministerio de Guerra y Marina. Allí hemos tenido acceso y examinado las 80 cajas de material clasificado como Organización Nacional 1861-1888. En este acervo documental poco frecuentado por historiadores no militares pudimos explorar una numerosa cantidad de testimonios y fuentes de diversa índole vinculados con el Colegio Militar en sus primeros años de existencia: partes militares, órdenes generales, actos de justicia militar y sanciones disciplinarias, numerosas cartas de familiares, madres, padres, hermanos, dirigidas a distintos jefes militares o al Ministerio de Guerra y Marina. El análisis de esa documentación nos ha permitido informarnos acerca del funcionamiento de la estructura militar tanto en épocas de relativa paz como en el contexto de un enfrentamiento militar. También nos ha proporcionado material para analizar la relación entre la guerra y la sociedad, mostrando la presencia del fenómeno de la movilización militar y la violencia en la vida cotidiana. Hemos consultado las memorias presentadas al Congreso por el Ministerio de Guerra y Marina de aquellos años (18621881), éstas se encuentran en el Servicio Histórico del Archivo del Ejército y en la biblioteca del Archivo General de la Nación (AGN). Este material ha sido

$9 \quad$ Macías, Flavia. “Orden y violencia política. Argentina, 1870-1880”, p. 236.

10 El recorte cronológico establecido (1869-1880) comprende el período que ocurre desde el momento de creación del Colegio Militar (1869) hasta los sucesos vinculados con el enfrentamiento entre las fuerzas de Buenos Aires y el Ejército Nacional (1880) donde, además de triunfar las fuerzas nacionales, se consolida el modelo militar que responde al Estado centralizado. El trabajo se concentra en la década de 1870, aunque también se mencionan algunas derivaciones sociales e institucionales posteriores que alcanzan hasta el siglo $\mathrm{xx}$. 
un importante insumo para nuestra investigación, proporcionando datos sobre los movimientos de entradas y salida de personal, actividades del Colegio Militar y diversos proyectos tendientes a la profesionalización de las Fuerzas Armadas. ${ }^{11}$ El examen de la prensa y los debates parlamentarios también fue de suma importancia para el trabajo realizado. En la Biblioteca del Archivo General de la Nación (AGN) hemos analizado distintos debates parlamentarios ocurridos en épocas de movilización militar o discusiones en torno a proyectos relacionados con la organización militar. Los archivos y colecciones particulares de militares, políticos, y otros hombres públicos asentados en la sala VII del AGN han sido de gran utilidad, como el fondo Domingo Faustino Sarmiento del Archivo Museo Sarmiento o los fondos documentales de Julio A. Roca e Ignacio Rivas, localizados en el Museo Roca. A ello se suman los relatos y memorias escritas de algunos jefes y oficiales que pasaron por las aulas del Colegio Militar de la Nación.

\section{REFORMAS INSTITUCIONALES EN LA ORGANIZACIÓN MILITAR (1868-1874)}

Sarmiento fue el candidato propuesto por los oficiales del ejército, subordinados a Mitre en su rol de Comandante en Jefe de las Fuerzas Armadas, cuando el candidato natural a la sucesión mitrista parecía ser Rufino de Elizalde. El triunfo de Sarmiento expresaba en gran medida el descontento de la oficialidad por el estado de la organización militar durante la Guerra en el Paraguay y las rebeliones en el interior del país. Como veremos a continuación, algunas de las demandas vinculadas con la necesidad de lograr una mayor modernización en el ejército serán atendidas durante su gestión presidencial (1868-1874).

Sobre las huellas todavía frescas de ese enorme fenómeno social que fue la Guerra de la Triple Alianza, a partir de la salida de Mitre se empezaron a poner en cuestión algunos aspectos relacionados con la organización militar. Los cinco años de campaña militar internacional significaron una prueba de fuego para el todavía incipiente Ejército Nacional, un gran aprendizaje para los soldados y oficiales que lograron regresar del frente. ${ }^{12}$ La exigencia de

11 No hubo presentación de memorias para los años 1867, 1874 y 1880. Los motivos de esta ausencia están vinculados con las convulsiones políticas que demandaron todas las energías del gobierno nacional durante esos períodos. En 1867 se produjeron las rebeliones en el interior, luego de la derrota de Curupaytí en la Guerra de la Triple Alianza. Los años 1874 y 1880 fueron ciclos de cambio de gobierno marcados por la agitación derivada de los procesos electorales. Estos desembocaron en las dos guerras que debió enfrentar la autoridad nacional: contra los mitristas en 1874 y frente a las fuerzas de Tejedor en 1880 .

12 Un estudio con múltiples acercamientos y distintas perspectivas acerca de este conflicto: Garavaglia y Fradkin, A 150 años de la Guerra de la Triple Alianza contra el Paraguay. 
profesionalizar la organización militar en todos sus niveles, desde la conducción y preparación para el combate, hasta las relaciones entre la política militar con el poder civil y la sociedad fueron colocados entre los temas pendientes por resolver. Las conclusiones provisorias y contundentes que dejaba como saldo el conflicto de la Triple Alianza es que todas las carencias de una organización militar deficiente se traducían en vidas humanas perdidas, tiempo de campaña y enormes costos materiales. ${ }^{13}$ La falta de disciplina y del llamado "espíritu de cuerpo" se expresaba en forma de motines y deserciones que obligaban a sancionar ejemplarmente a sus instigadores con el fin de evitar la temida "desmoralización" de los batallones. ${ }^{14}$ Desde la visión crítica de una nueva generación de oficiales curtidos en las trincheras del Paraguay estas cuestiones comienzan a ser asociadas con la política militar que los origina. ${ }^{15}$

La década de 1870 fue una época caracterizada por los diferentes intentos de modernización de las fuerzas armadas. Las novedades impulsadas por estos años estuvieron orientadas en conjunto a lograr las reformas necesarias para establecer las bases de un ejército nacional profesional. Para ello, la organización reglamentaria y la formación de sus cuadros habrían de proyectarse en los protocolos administrativos que fueran propios de la estructura castrense. El proyecto de Sarmiento de separar al ejército de las luchas facciosas mediante su profesionalización encontraba una cierta afinidad con el clásico planteo de Carl Von Clausewitz ${ }^{16}$ acerca de la naturaleza dual de la guerra. Según Clausewitz, la guerra era simultáneamente una ciencia autónoma con sus propios procedimientos y es a la vez también una actividad subordinada en tanto que sus fines provienen fuera de sí misma. La guerra tiene su propia gramática, pero no su propia lógica. La lógica militar es definida por

13 La denominada "estrategia del número" fue duramente criticada por oficiales como Daniel Cerri y Julio Roca. Este último describía su fracaso en la Triple Alianza: “Aquella guerra (...) duró tanto, porque ni en nuestros generales, ni en los brasileños, ni en el campo paraguayo, hubo la chispa militar necesaria. De una y otra parte la estrategia ha consistido en amontonar gente; el primero á quien se le agotaba esta tenía que sucumbir. Así fue. Los paraguayos se agotaron primero. Nosotros triunfamos". Carta de Roca a Sarmiento en 1875. Publicada en el diario La Tribuna el 4 de agosto de 1875.

14 Aparecen algunos testimonios sobre la aplicación de la pena de muerte en el Ejército en las "memorias" del general de división inglés I. Fotheringham, de larga trayectoria en el Ejército argentino: La vida de un soldado, Reminiscencias de las fronteras, pp. 155 y siguientes. También: Comandante Prado, La guerra al malón, pp. 103-110.

15 La ineficiente situación de las proveedurías para el Ejército será duramente cuestionada no sólo por quienes padecieron sus efectos, sino también por los opositores políticos del gobierno de Mitre que la asociaban con negociados y prácticas corruptas entre el gobierno nacional, algunos de sus allegados comerciantes de Buenos Aires que firmaron importantes contratos de provisión para el Ejército de Campaña y varios jefes militares mitristas. Pomer, León, La guerra del Paraguay Gran Negocio! 
el poder político en función de sus objetivos y la gramática es la ciencia de lo militar. ${ }^{17}$ Preparar militares profesionales implica el reconocimiento de aquella naturaleza dual de la estructura militar, separarlos de la lógica de la política y subordinarlos a ella. ${ }^{18}$ Además, emergía la preocupación por la llamada moralización de las costumbres en los soldados y la disciplina que pretende hacer dóciles los cuerpos. Estos asuntos parecen estar siempre presentes en la justificación de las prácticas disciplinarias y punitivas que buscan hacerlos aptos para la lealtad y subordinación requerida. Entre los extremos de la imposición violenta, que desata acciones de resistencia frente a la arbitrariedad impuesta por los mandos militares, y la autoridad consensuada, en la práctica de los cuarteles y campamentos militares se negocian las relaciones de obediencia en el marco de una construcción cultural de creencias y prácticas que rivalizan en un escenario de conflicto. ${ }^{19}$ La política militar que propone Sarmiento intentará separar esas prácticas basadas en relaciones personalistas por un modelo burocrático que prepare oficiales para responder de manera impersonal al Estado nacional y ése es uno de los desafíos que se plantea enfrentar la instauración del Colegio Militar.

\section{La LEY DE REClutamiento y la Guardia Nacional}

La primera ley nacional sobre reclutamiento de efectivos para el ejército permanente (1872) estaba inspirada por aquella vieja fórmula tendiente a "desarraigar la localización de los cuerpos que destruye toda idea de un Ejército

17 Siguiendo ese planteo podemos afirmar que el objetivo del poder político — representado en la figura de Sarmiento- era el de crear las condiciones de posibilidad de una gramática de la guerra, separada de la política por su especialización en las técnicas de manejo de la violencia, que a su vez reforzara su papel de sujeción a los fines estipulados por la política.

18 Entre aquellos propósitos, el relegado proyecto de Código Militar, la ley de reclutamiento de 1872 - que habilitaba el sorteo universal para todos los ciudadanos-y la puesta en funcionamiento del Colegio Militar para la formación de oficiales fueron las bases a implementarse para conseguir la consolidación de una estructura militar nacional acorde con la evolución del Estado nacional. Aunque esos tres proyectos no eran algo nuevo en la década de 1870 ni fueron los únicos, serían los que aparecían con una mayor necesidad de concreción cuando se examinaba la urgencia de reformas modernizadoras de la estructura militar. De ellos, el Código Militar nunca se sancionaría — deberá esperar hasta fines de siglo- la ley de reclutamiento se aprobaría en 1872, pero el sistema de sorteo universal que disponía nunca se puso en práctica efectivamente - también tuvo su dilación hasta fin de siglo-, y por ello el Colegio Militar, concebido como academia de formación de oficiales será la única de esas instancias llevada a la práctica desde principios de la década de 1870.

19 La historia cultural ha puesto en entredicho la concepción antropológica tradicional de cultura como "un mundo concreto y acotado de creencias y prácticas" entendiendo a las culturas como escenarios de conflicto que se hallan débilmente integrados. William Sewell, "The Concept(s) of Culture", pp. 35-61. 
Nacional", ${ }^{20}$ aunque más precisamente dirigida al objetivo de alejar el control de la Guardia Nacional del poder de los gobiernos provinciales y colocarlo definitivamente bajo la órbita del poder nacional. Según dice Natalio Botana, al interpretar las ideas militares de Sarmiento, la GN era una organización militar que adquiría las características del medio que las engendraba. Así, cada sociedad proyectaba sus características sociales y la fisonomía de sus luchas en la composición y funcionamiento de la Guardia Nacional. ${ }^{21}$ Para acabar con esa diversidad marcada por el origen, Sarmiento insistía en definir a la GN a partir de la suma de sus componentes, "Los nacidos en la República Argentina son miembros de la Guardia Nacional, Estén enrolados o no, entiéndanlo bien". En ese sentido, la GN debería constituir una abstracción hasta el momento en que el Estado nacional decida su reunión, un concepto que en la práctica compone a todos los ciudadanos de la Nación y ya no debe ser identificada con aquellas milicias provinciales en manos de los "caudillos". ${ }^{22}$

En septiembre de 1872 el Congreso de la Nación sanciona una nueva ley para el reclutamiento del ejército. En ella se disponen las condiciones para el alistamiento de voluntarios, enganchados, destinados y la proporción del número de reclutas en forma de contingente con que cada provincia debía contribuir a la remonta del Ejército de Línea. Es la primera disposición que adecúa a los contingentes requeridos de acuerdo con la población existente en

\section{Estado argentino, p. 99.}

21 Dice Botana interpretando a Sarmiento: "Es que la precaria organización militar estaba tan ligada al modo de ser de las sociedades que en ella se radicaban, según predominasen en una y otra situación, los instintos igualitarios, la distribución de la propiedad y los privilegios de los poderosos. En Estados Unidos, la milicia era una igualitaria "manifestación de la república"; en Francia, en 1845, "la guardia nacional propietaria servía para mantener la monarquía, y contener al pueblo artesano, declarado no ciudadano"; en España, "formada de burgueses y de pueblo, ha servido para apoyar con sus bayonetas a este o el otro partido que se han disputado el mando, hasta que ha sido suprimida"; y en chile, era "una servidumbre impuesta por la sociedad culta a la muchedumbre inculta". Botana, La tradición republicana. Alberdi, Sarmiento y las ideas políticas de su tiempo, pp. 380-381. Esta visión tradicional ha sido enriquecida y contrastada por la nueva historiografía sobre la Guardia Nacional que examina los conceptos de ciudadanía armada, la circulación de los valores republicanos y la expresión de modelos de Estado alternativos expresados en esa institución, desde la perspectiva de los actores contemporáneos. Remitimos a los trabajos mencionados en las notas 5 y 27. Los principios y formas de hacer política fuertemente anclados en valores republicanos chocaron contra los intentos de concentración del poder. Sabato, "Hacer política en tiempos de república", pp. 37-38.

22 Unos años después, como representante del gobierno nacional en las disputas con el gobierno de la provincia de Buenos Aires (1879-1880), Sarmiento insistirá en la idea de que no hay ciudadanía provincial, sino únicamente nacional y por ello el principio de la ciudadanía armada contenido en la Constitución Nacional sólo se expresa en las fuerzas que responden al gobierno nacional. Mendizábal, Historia de un crimen, p. 21. 
cada provincia según el censo nacional de $1869 .{ }^{23}$ En 1872 se crea la Escuela Naval que comienza a funcionar a bordo del buque de guerra General Brown. El salto tecnológico en la fuerza naval obligaba a la modernización de las fuerzas de mar y con esa perspectiva el comandante del buque, Coronel Rosetti, mayor Clodomiro Urtubey, apoyado por un grupo de marinos propuso a Sarmiento la creación de una escuela náutica separada del Colegio Militar. Sarmiento estuvo de acuerdo y el 5 de octubre de 1872 dispuso la organización de la Escuela Naval Militar, puesta bajo la dirección de Urtubey con asiento en el General Brown, que de esta forma se convierte en el primer buque escuela de la marina argentina. De este modo, 1872 se convierte en el año donde quedarán estructuradas las bases para la futura profesionalización del ejército, aunque este proceso se demorará todavía otras dos décadas más. ${ }^{24}$ Curiosamente, 1872 es el año de aparición del Martín Fierro, personaje cuya existencia transcurre atravesada por la dureza y rigor de las disposiciones militares. ${ }^{25}$

La ley de reclutamiento se daba en un contexto de fuertes cuestionamientos al poder ejecutivo nacional por las intervenciones federales y sobre el rol del ejército como brazo armado de la centralización. ${ }^{26}$ De esta nueva legislación hay que destacar, por un lado, la aparición de algunos aspectos novedosos, así como también la confirmación de la vigencia de disposiciones del antiguo régimen. ${ }^{27}$ La medida plantea como novedad la universalización del servicio militar en el Ejército de Línea a través de la convocatoria de contingentes de la Guardia Nacional en la que deben participar todos los individuos hombres y mayores de edad por su condición de ciudadanos. El contingente se conformaría a través del sistema de sorteo en cada localidad entre todos los hombres de

23 Argentina. Ejército, Ley de reclutamiento, Imprenta Americana, Buenos Aires, 1872, folleto de 14 páginas.

24 García Molina, La prehistoria del poder militar en la Argentina, La profesionalización, el modelo alemán y la decadencia del régimen oligárquico.

25 Ese mismo año se había dado a publicidad la obra del coronel Álvaro Barros, de amplia difusión dentro de la élite política, en la que se cuestionaba severamente el estado de la organización militar en todos sus niveles y, entre otras reformas, reclamaba una ley de reclutamiento acorde con los tiempos republicanos que superara a las antiguas ordenanzas españolas aún vigentes en el ejército. Barros, Fronteras y territorios federales de las pampas del sur. El autor dedica su obra al vicepresidente Adolfo Alsina.

26 Zimmermann, "En tiempos de rebelión. La justicia federal frente a los levantamientos provinciales, 1860-1880”, pp. 245-273.

27 Aunque el sistema no se hizo efectivo hasta 1887 cuando el presidente Juárez Celman emitió un decreto para reglamentar el modo de ejecución del sorteo entre todos los ciudadanos. Cucchi, Laura, "Estado, política y cuestión militar entre 1880 y 1890 . El Partido Autonomista Nacional y la organización de un nuevo Ejército de la Nación”, pp. 75-76. La ley de 1872 fue reflotada y discutida a la hora de institucionalizar el servicio militar obligatorio en 1901, la ley 4031, conocida como "ley Ricchieri". 
18 a 45 años hasta completar las plazas requeridas por el ejército regular. ${ }^{28} \mathrm{~A}$ continuación de esta medida se incluye la posibilidad de habilitar un personero "que sustituirá en todos sus derechos y obligaciones al reemplazado". ${ }^{29}$ Por otro lado, la ley de reclutamiento reafirma explícitamente en su artículo $9^{\circ}$ que una vez firmado el contrato por parte del soldado "quedará sujeto en todo a las Ordenanzas Militares" ${ }^{30}$ que no son otras que las antiguas leyes militares de la época de Carlos III (promulgadas en 1768) y los sucesivos bandos y disposiciones derivados de ellas. Otro aspecto que queda plasmado será el de la asociación entre castigo penal y servicio militar expresado en la figura del destinado. Son destinados "por el término de su condena, los que, con arreglo a las Leyes penales, sean sorteo castigados con el servicio de armas" siendo luego "puntualmente dados de baja, después de cumplir su condena". ${ }^{31}$

La medida tiene su fundamento en los fines establecidos por la Constitución Nacional para la Guardia Nacional, como reserva del Ejército de Línea. Argentina. Ejército, Ley de reclutamiento, op. cit., pp. 9-10. En la práctica implicaría el fin de idea la ciudadanía armada para los GN enviados al Ejército, pues los miembros de la tropa no votan. La asociación entre servicio militar y ejercicio del sufragio fue un motivo central de debate público durante la década de 1870. En las sesiones de la Cámara de Diputados de la Nación del año 1873 dedicadas a la reforma de la ley nacional de elecciones se discutió el requisito de estar enrolado en la Guardia para poder votar. Quienes defendían la vinculación entre el deber de enrolamiento y el derecho a voto consideraban que el servicio de armas y el ejercicio del sufragio eran dos componentes inherentes e indisociables de la ciudadanía, a la vez que planteaban una relación directa entre deberes y derechos ciudadanos. Macías y Sabato, "La Guardia Nacional: Estado, política y uso de la fuerza en la Argentina de la segunda mitad del siglo XIX", pp. 76-80.

Ibid., p. 10 .

Ibid., p. 6.

31 Ibid., p. 7. La figura del destinado a cumplir una condena con el servicio a las armas constituye el núcleo sobre el que descansa la visión punitiva y el estigma que pesa sobre el Ejército de Línea. Por ello la idea de habilitar el sorteo entre los guardias nacionales para obtener soldados del Ejército no será bien recibida y quedará como una posibilidad a futuro antes que una práctica de aplicación inmediata. En 1877 el propio Ministro Alsina se resiste a aplicar el sorteo que convierte a los guardias nacionales en soldados del Ejército de Línea, prefiriendo movilizar a la GN para el servicio de frontera: "Aquí se toma un joven honrado, se le lleva á la frontera y se le pone a su derecha un enganchado, un hombre que ha vendido su carne, su persona, y á su izquierda un malvado, un presidiario condenado á tantos años de trabajos forzados. Esta sería la situación y esto se tendría que hacer luego, si por otros medios, la Cámara no habilita al Gobierno para llevar adelante el pensamiento que tiene de asegurar las fronteras de la República". Diario de Sesiones (1877). Cámara de Diputados de la Nación, Buenos Aires, Argentina, sin editor. Sesión del 6 de junio de 1877, p. 191. Es interesante examinar en el argumento de Alsina la idea de la injusticia que suponía colocar en pie de igualdad al Guardia Nacional con el soldado del ejército. El enganchado - contratado-, "hombre que ha vendido su carne, su persona" y el destinado a las armas "malvado, presidiario condenado a trabajos forzados" no podrían convivir con el ciudadano "joven honrado" y Guardia Nacional. Aquella percepción de injusticia fue la que llevó a 
En su origen inmediato, la ley de reclutamiento de 1872 y las restantes medidas destinadas a sentar las bases de la universalidad del servicio militar y la profesionalización de la carrera de las armas deben visualizarse en su contexto de producción. Atrás ha quedado la guerra en el Paraguay y las amenazas del antiguo federalismo neutralizadas luego de las primeras batallas contra el jordanismo entrerriano. Una paz relativa en el contexto de resistencias provinciales que amenazaban la autoridad nacional impulsa algunos avances institucionales del poder nacional que se propone destinar una mayor cantidad de recursos materiales y humanos para encarar el avance de la frontera. ${ }^{32}$ Cuando el Ministro de Guerra Martín de Gainza presenta al Congreso la Memoria de su cartera en 1872 dice que es la primera vez que "se presenta ante el Congreso el Departamento de la Guerra libre de toda complicación militar así en el interior como en el estrangero (...) de manera que el Congreso podrá dirijir su atención y sus luces á legislar sobre las necesidades del ejército sin la coacción que producen situaciones anormales y exigencias violentas del momento." ${ }^{33}$

La política tendiente a regularizar la situación del ejército por parte del gobierno nacional muestra - nuevamente - que no puede llevarse a cabo de manera completa y efectiva, pues es la misma dinámica de lo irregular y la arbitrariedad la que permite contar con mayor cantidad de efectivos cuando hay necesidad de hombres para el ejército. El propio ministro reconoce que "El ejército de línea se compone de seis mil cien hombres, distribuidos en las tres armas, de que un mil setecientos se hallan cumplidos, algunos, en doble tiempo del de su empeño". ${ }^{34}$ Aunque agrega que por el momento no es posible otorgar la baja a tanta cantidad de individuos cumplidos de su servicio, en primer lugar, porque no hay muchos individuos dispuestos a engancharse como reclutas. En segundo lugar, no se puede reenganchar a los que han cumplido con el tiempo

Alsina a desestimar la aplicación el mecanismo del sorteo previsto en la ley de reclutamiento de 1872 .

32 Ratto, "El frustrado proyecto de avance territorial del Estado Nacional entre 1869-1872", pp. 93-119. Ratto, "Estado y cuestión indígena en las fronteras de Chaco y La Pampa (18621880)", pp. 7-28.

33 Memoria de Guerra, Ejército Argentino, EMGE, Servicio Histórico, mayo de1872, p. 3. Hemos dejado como asignatura pendiente para un estudio posterior la reconstrucción de algunos debates dados en la opinión pública, la prensa y las sesiones de la Cámara de Diputados y Senadores de la Nación, para confrontar la política oficial con algunas visiones alternativas que contrastan con la política militar impulsada desde el gobierno nacional. Sobre las reformas militares encaradas a partir de 1880 y la alteración de los vínculos entre nación y provincias: Cucchi, Laura, "Estado, política y cuestión militar entre 1880 y 1890. El Partido Autonomista Nacional y la organización de un nuevo Ejército de la Nación", pp. 58-85. Cucchi y Dapelo, "La política en las provincias durante la emergencia y consolidación del Partido Autonomista Nacional, pp. 84-93.

${ }_{34} \quad$ Ibid., p. 4. 
de servicio o condena, es decir, volver a firmar el contrato de enganche, pues el presupuesto con el que cuenta el Ministerio "no alcanzaría para pagar los reenganches de la mitad de los cumplidos", entonces lo mejor es mantenerlos en servicio activo hasta que las condiciones institucionales y presupuestarias permitan esas innovaciones.

En aquel marco de precariedad se desenvuelve la política militar, habiendo expresado la voluntad de mejorar el servicio del ejército dice el ministro que el gobierno se ha visto en "la necesidad de ocurrir á los contingentes de Guardias Nacionales con todos sus inconvenientes y gravámenes. La Guardia Nacional reclutada y remitida violentamente, dá los peores resultados en el servicio, habiéndose repetido los casos de deserción en masa con armas y caballos, abandonando los fortines cuya defensa les había sido encomendada". ${ }^{55} \mathrm{El}$ servicio de la Guardia Nacional, aquel simbólicamente identificado con la ciudadanía armada, el honor y el deber de los ciudadanos argentinos de armarse en defensa de la patria y sus instituciones, se veía continuamente desnaturalizado como consecuencia de la violencia de los contingentes enviados por la fuerza. ${ }^{36}$ La coronación de aquella distorsión era expuesta por el propio Ministro y podía verificarse en las fronteras del sur, donde "los indios de Catriel á más del servicio que les está encomendado, prestan el de escoltar a los guardias nacionales que hacen descubiertas y guarnecen fortines para evitar su deserción". 37

La reforma militar expresada en la ley de reclutamiento de 1872 funcionaba en varios niveles que nos permiten vincular a la guerra con los procesos de construcción estatal. ${ }^{38}$ Una guerra "entendida como institución interna y ya no solamente como acontecimiento bruto de la batalla", ${ }^{39}$ nos permite reconocer que la modificación en las funciones y el modo de reclutamiento de la GN implica una trasformación en el modo de preparar y organizar la guerra. El modelo militar que el gobierno nacional pretendía superador respecto a la organización de las milicias provinciales encuentra en la ley de 1872 una

$35 \quad$ Ibid., p. 5.

36 Algunos estudios sobre la GN en las sociedades de frontera han puesto en duda o relativizado esta asociación entre milicias y ciudadanía. Véase Canciani, "resistencias a la obligación de armarse. Reclutamiento y servicio militar en la Guardia Nacional de frontera" y Literas, Vecindarios en armas. Sociedad, Estado y milicias en las fronteras de Pampa y Norpatagonia (segunda mitad del siglo XIX).

37 Memoria de Guerra, Ejército Argentino, EmGe, Servicio Histórico, mayo de1872, p. 6. Sobre la política de frontera véase especialmente: Ratto, "Estado y cuestión indígena en las fronteras de Chaco y La Pampa (1862-1880)", pp. 7-28.

38 Tilly, Coerción, capital y los Estados europeos 990-1990. Zimmermann, Eduardo, "Guerra, fuerzas militares y construcción estatal en el Río de la Plata, siglo XIX. Un comentario”, pp. 185-204.

39 Foucault, Genealogía del racismo, p. 132. 
legislación directamente relacionada con el avance del Estado nacional. En primer lugar, reorganizando el modo de hacer la guerra, pues el poder nacional proyectaba un modelo de Estado centralizado diferente al modelo estatal representado por la Guardia nacional, entendida como milicia provincial. ${ }^{40} \mathrm{En}$ segundo lugar, la efectividad de la puesta en práctica de esas reformas militares significaría el avance material del modelo de Estado centralizado representado militarmente en el ejército profesional. Si la guerra hizo al Estado y el Estado hizo la guerra, ambas estructuras irán evolucionando de manera conjunta en una relación de recíproca influencia. En tercer lugar, la reforma militar de 1872 implicaba la posibilidad de obtener un mayor control del territorio nacional por parte del Estado. Una presencia territorial que todavía no aparece con firmeza en las zonas de frontera y más allá, en el "desierto" habitado por las sociedades indígenas. $^{41}$

\section{El Colegio Militar de la Nación y la educación de los ASPIRANTES EN LA DÉCADA DE 1870}

En estos tiempos, no obstante admirar el pueblo el valor y las glorias del Ejército, casi nadie quería ingresar en la carrera militar. Pues los batallones, cuerpos, regimientos y demás instituciones de esta naturaleza, eran considerados por nuestros ciudadanos como cuerpos de corrección o establecimientos de punición. Por consiguiente, yo sabía con seguridad que la negativa de mi familia la tendría en masa; no había que pensar en solicitar el beneplácito de mis padres. ${ }^{42}$

Sarmiento era un gran admirador de las doctrinas militares europeas, sobre todo las de Francia, y estaba convencido de que preparando soldados de carrera de acuerdo con un programa científico se daría el primer paso para acabar con la improvisación y avanzar hacia la modernización del ejército. ${ }^{43}$ Con estas

40 Estos dos modelos se enfrentarán en 1880 cuando las fuerzas nacionales dobleguen a las milicias porteñas. Sabato, Buenos Aires en armas. La revolución de 1880.

41 El "territorio nacional" no refiere a una asociación esencialista y tampoco es un concepto concebido como pura geografía, sino que hablamos de él como una construcción histórica y jurídico-política definida por el control de un cierto tipo de poder. Foucault, Microfisica del poder, pp. 124.

42 Daza, Episodios Militares, p. 241.

43 Al mismo tiempo que se proyectaba la creación del Colegio Militar, un grupo de oficiales propone al presidente la idea de agregar cursos de náutica con el fin de preparar oficiales de marina. Los responsables del proyecto plantean una necesidad fundaba en los grandes cambios tecnológicos que se producían en la época, avances que en el plano militar irían revolucionando las condiciones y los modos de hacer la guerra. En 1872 se crea la Escuela Naval que comienza a funcionar a bordo del buque de guerra General Brown. El salto tecnológico en la fuerza naval estaba dejando rápidamente atrás a los viejos marinos de los 
ideas retoma el antiguo proyecto de Mitre de organizar una escuela militar, iniciado poco antes de la Guerra en el Paraguay y truncado por ese conflicto. Con la ayuda de su ministro de Guerra, Martín de Gainza, se propone poner en marcha el Colegio Militar en $1869 .{ }^{44}$

La trayectoria del Colegio Militar de la Nación durante su primera década de existencia, expresada en la vinculación de sus alumnos, egresados, autoridades y docentes con el poder político, la sociedad y su articulación con el ejército de su tiempo, dará cuenta de la ardua tarea que implica promover una "instrucción científica" de los nuevos cuadros. La academia se propone alejada de los vicios y prácticas que se intentan desterrar en el ejército y por ello los aspirantes estarían sometidos al estricto control de un régimen disciplinario ajustado al texto de la "Ordenanza Militar en todo lo que concierne a la subordinación, el respeto debido a los Superiores, la prontitud y exactitud en la ejecución de las órdenes, etc.". ${ }^{45}$

El lugar elegido para iniciar las actividades fue la antigua residencia de Rosas en San Benito de Palermo. Allí funcionaba durante el gobierno de Mitre (1862-1868) la Escuela de Artes y Oficios, que fue el antecedente más cercano del Colegio Militar. La casona de Palermo había sido acondicionada para establecer la sección militar de dicha escuela, destinada a la instrucción

veleros de madera; el vapor, el buque blindado, el cañón rayado de retrocarga y la aparición del torpedo obligaban a la modernización del hombre de mar que en adelante debería ser un profesional debidamente preparado. De Marco, "De la Marina 'fluvial' a la Marina 'atlántica"', pp. 177-188.

$44 \quad$ El 9 de agosto de 1869 el Poder Ejecutivo elevó al Congreso el proyecto de ley por el que se creaba la institución. Aprobado en menos de dos semanas por ambas cámaras, la ley fue sancionada el 11 de octubre. El proyecto de ley planteaba: "Artículo 1: Autorizase al Poder Ejecutivo para la formación de una Escuela Militar. Artículo 2: Autorizase igualmente, para gastar hasta la suma de cinco mil pesos fuertes en los gastos de instalación, y mil quinientos cincuenta al mes, en los ordinarios de la misma. Artículo 3: Comuníquese". Diario de Sesiones, Cámara de Diputados, 17 de septiembre de 1869, p. 369. En diputados el proyecto fue aprobado tanto en general como en particular. Puesto a consideración del Senado, la votación en general fue afirmativa por mayoría, pero al discutirse en particular el artículo primero, pidió la palabra el senador Oroño para oponerse al mismo: "voy a hacer una ligera observación que demostrará a la Cámara lo ineficaz de esta creación (...) porque una escuela militar, para responder a los objetivos que se deben tener en vista es necesario gastar cien o doscientos mil pesos al año. Esta es la razón por la que he de votar en contra". El senador Granel, miembro informante de la Comisión de Guerra que adoptó el proyecto llegado desde el Poder Ejecutivo, dirá que "aunque los elementos que se votan no son bastante para atender a una exigencia reclamada por las necesidades y conveniencias del país (...) también ha creído - la Comisión de Guerra - que era necesario empezar por algo y que llevar a cabo una obra de esta importancia, importaba poner la primera piedra sobre la que se ha de levantar el edificio". Diario de Sesiones, Cámara de Senadores, Sesión del 7 de octubre de 1869, p. 1131. El proyecto fue aprobado en esta sesión.

45 Reglamento del Colegio Militar Nacional con sus modificaciones, Buenos Aires, Imprenta Especial para Obras de Pablo Coni, 1875, p. 25. 
de reclutas, aunque fue una experiencia truncada al estallar la guerra en el Paraguay. Sarmiento se ocupó personalmente de nombrar una comisión de militares que fue la encargada de redactar el reglamento que contendría todas las disposiciones que formarán al oficial profesional egresado del Colegio. ${ }^{46}$ En pocos meses éste fue redactado y aprobado por el presidente el 12 de marzo de 1870, quien además designó como director del colegio al militar de origen húngaro Juan Czetz. ${ }^{47}$ El primer reglamento de la institución establecía el perfil requerido por los jóvenes aspirantes. La educación militar estaría destinada a los:

- Hijos de militares muertos en el campo de batalla.

- Huérfanos e hijos de militares y de los empleados de la administración en general, determinado el número de dos por cada provincia.

- Las demás becas - 50 en total- serían asignadas por el gobierno a los solicitantes que, a su juicio, merecieran tal beneficio. ${ }^{48}$

Los estudiantes serían becados por el gobierno y los requisitos para optar por una de las 50 becas disponibles eran "Tener buena salud y adecuada robustez. Saber leer, escribir y conocer la aritmética elemental. Tener 12 a 14 años de edad." ${ }^{49}$ El primer plan de estudios fijaba una duración de cinco años para la totalidad de los cursos. Estaba estructurado en cinco períodos que incluían cursos de matemáticas, castellano, historia, geografía, cosmografía, ordenanza táctica de las tres armas, planimetría, dibujo, inglés, francés y ejercicios de tiro y esgrima. Los exámenes finales serían supervisados por una comisión nombrada por el Poder Ejecutivo, cuyo primer presidente fue el general Emilio Mitre. Una vez iniciada la tarea educativa y durante más de un año desde su inauguración, el número de estudiantes no llegaría a cubrir las 50 becas. Al iniciar el año 1871 se alcanza el número de treinta y seis "aspirantes

46 La comisión redactora del reglamento estaba compuesta por el Brigadier General Emilio Mitre, General Indalecio Chenaut, Coronel Mariano Moreno, Coronel Juan Czetz y el Sargento Mayor Lucas Presloan.

47 Czetz era un militar húngaro de nacimiento, pertenecía a una familia de soldados y había cursado en la Academia Militar de Viener-Neustadt hasta obtener el grado de teniente, con el que se incorporó al ejército del Imperio Austrohúngaro. Cuando Hungría se rebeló al dominio austríaco Czetz combatió en las filas de su país natal, destacándose al punto de alcanzar el grado de general a los 27 años de edad. La derrota de los húngaros lo obligó a exiliarse en diversos países. En España conoció a quien fue su mujer, perteneciente a la familia argentina Ortiz de Rosas, con quien arribó al país en 1860. Fue primero agrimensor y luego se incorporó al Ejército Argentino en la sección de ingenieros, siendo ascendido por Mitre al grado de Coronel y habiendo ganado prestigio en Argentina como militar, hombre de ciencia e incluso escritor. Scenna, Los militares, p. 81.

48 Reglamento del Colegio Militar con sus modificaciones, Buenos Aires, Imprenta Especial Para Obras de Pablo E. Coni, 1875, pp. 23-24.

49 García Enciso, Historia del Colegio Militar de la Nación, p. 31. 
a oficiales" en los cursos regulares. ${ }^{50}$ La escasez de aspirantes obligaría a permitir el ingreso de algunos estudiantes que no cuadraban con los requisitos de admisión; ingresaron algunos mayores de 14 años y otros menores de los 12 años estipulados. Hubo aspirantes que no rendían satisfactoriamente los exámenes de ingreso que consistían en una evaluación de aritmética básica, lectura, escritura y dictado, pero si el examen de su constitución física aparecía como de "condición robusta" serían admitidos. ${ }^{51}$ Una constitución física "débil" tendría un mayor peso negativo que un mal examen o el no cumplir con los límites de edad a la hora de rechazar a los candidatos. ${ }^{52}$

Para 1872 el colegio contaría con 56 estudiantes, 18 cursando el primer año, 24 en segundo y 16 en tercero. ${ }^{53}$ A fines de 1873 se graduaría la primera camada de estudiantes, un total de 13 oficiales. ${ }^{54}$ Fue en octubre de 1873 , a raíz de la segunda guerra contra López Jordán, luego de que cuatro alumnos de $4^{\circ}$ año fueron movilizados por orden del ministro Gainza para completar el cuadro de oficiales del Regimiento $1^{\circ}$ de Caballería que operaría en las cercanías de Paraná. ${ }^{55}$ En la misma fecha el gobierno entregó los despachos de subteniente al resto de los alumnos del $4^{\circ}$ año y con ello los primeros egresados del Colegio se integraron al ejército. El primer reglamento del Colegio establecía que "a los 17 años, los seis alumnos más distinguidos entrarían como Tenientes $2^{\circ}$

50 “Aspirantes” será la denominación que se da a los estudiantes hasta 1894, cuando pasa a llamárseles "cadetes".

$51 \quad$ Solicitud de beca para el Colegio militar, 19 de abril de 1875: "El joven Esteban Manquelo para quien se solicita una beca en el Colegio Militar ha dado el examen previo de Reglamento y la clasificación obtenida es como sigue: lectura-regular, dictado-malo, caligrafía-malo, aritmética-conoce solo la operación de sumar y muy poco la de multiplicar. Teniendo 16 años de edad y aparentando muy buena constitución física (...) en vista de ello está en condiciones de ser aceptado". EMGE, Servicio Histórico, Organización Nacional, Caja 55, documento 16729 .

52 Informe del director Mariano Moreno al Ministro Alsina, 17 de agosto de 1875: "El joven Juan José Recalde (...) ha rendido el examen previo de reglamento obteniendo la clasificación de malo en aritmética y escritura y regular en lectura y dictado. Dice tener 13 años y aparenta una constitución débil. Sin embargo Vd. Resolverá lo que estime conveniente". Respuesta de Alsina, 18 de agosto de 1875: "No estando en condición de ser admitido en el Colegio Militar, el joven para quien se solicita una beca, no ha lugar y archívese”. EMGE, Servicio Histórico, Organización Nacional, Caja 57, Carpeta 279: Organización y operaciones, documento 17115 .

53 De ellos, 31 eran oriundos de Buenos Aires, 5 de Córdoba, 4 de Entre Ríos, 3 de Santa FE, 2 de Catamarca, 2 de Paraguay y 1 de cada una de las provincias: San Juan, San Luis, Corrientes, Tucumán, Salta, Mendoza, Jujuy, La Rioja y Santiago del Estero.

54 Los trece egresados fueron: Sargento $1^{\circ}$ Distinguido Ramón Falcón, Sargentos $2^{\circ}$ Martin Gras, Rodolfo Kratzenstein, Rómulo Parkinson, Lázaro Hernández, Estanislao Maldones, Ángel Falcón, Alberto Capdevila, José Daza, Cabos $1^{\circ}$ Tomas Parkinson, Rodolfo Domínguez, Cabos $2^{\circ}$ Luis F. Correa y Ramón Correa. Historia del Colegio Militar de la Nación..., op. cit., p. 36 .

55 Sargentos $2^{\circ}$ José Daza, Martin Gras y Rodolfo Kratzenstein, Cabo $1^{\circ}$ Rodolfo Domínguez. 
á los cuerpos que elijan, quedando obligados á servir cuatro años; los otros pasarán a los cuerpos en calidad de Alférez y tienen la misma obligación de servicio". ${ }^{56}$ Sin embargo, la trayectoria de estos primeros años de vida del Colegio va sugiriendo algunas reformas sobre la marcha, impulsadas a partir de las contingencias de la militarización de la vida política antes que por los dictados de la ciencia militar. La incorporación de los futuros oficiales a las unidades, apresurada por los movimientos de la vida política, irá dificultando el cumplimiento estricto de las disposiciones reglamentarias. La necesidad de oficiales con formación teórica en un contexto de movilizaciones bélicas siempre latentes obliga a acortar los años de duración de la carrera. En 1875 se establece que desde el tercer año los alumnos puedan ser incorporados a las unidades de caballería o infantería, y como incentivo para quienes completen la formación de cinco años, podrían optar por incorporarse a un regimiento de artillería o el cuerpo de ingenieros. ${ }^{57}$

La escasa afluencia de postulantes se relacionaba con la evocación que hace José Daza — uno de aquellos primeros aspirantes - acerca de la consideración que la sociedad de su tiempo tenía sobre la carrera militar. La idea de que las unidades militares eran "cuerpos de corrección o establecimientos de punición" tenía su correlato en la cantidad de individuos destinados por delitos comunes a servir en esos cuerpos en donde también iban a parar los "vagos y malentretenidos", o los infractores a la ley de enrolamiento de la Guardia Nacional y otros tantos llevados por la fuerza de la arbitrariedad en el "contingente". ${ }^{58}$

En 1875 el ministro Alsina se muestra preocupado por una cierta idea que circula acerca de los destinatarios de la educación del colegio, quienes serían sólo jóvenes huérfanos o hijos de militares muertos en combate. Pasados cinco años desde su fundación, el Ministro planteaba la necesidad de cambiar aquellos prejuicios sobre los potenciales estudiantes del colegio. Desde su óptica aquella idea estaba asociada con una falsa apreciación que surgía de la interpretación literal del reglamento, Alsina afirmaba que "desnaturaliza la índole de la institución. Lo que se propuso no fue dar educación a los hijos de tales o cuales padres, sino fundar una casa de educación que diera a la

56 Reglamento del Colegio Militar Nacional con sus modificaciones..., op. cit., pp. 23-24.

57 Reformas dictadas por el Ministro Alsina en carta al Director del Colegio Militar: "Los alumnos que hayan dado exámenes completamente satisfactorios de todas las materias correspondientes á los tres primeros años, y de principios de estrategia podrán pasar como sub-tenientes ó Alféreces á los cuerpos de infantería o caballería. Los que terminen con igual resultado todo el curso de cinco años, pasarán a servir en el Regimiento de Artillería ó en el cuerpo de ingenieros. En igualdad de casos gozan de antigüedad los oficiales que hayan terminado sus estudios en el Colegio Militar". Reglamento del Colegio Militar Nacional con sus modificaciones, p. 57.

58 Daza, Episodios Militares, pp. 240-243. 
República oficiales instruidos siendo preferidos, en igualdad de condiciones, los huérfanos de militares". ${ }^{59}$ El ministro planteaba la necesidad de ampliar el ingreso para todos los jóvenes interesados en la carrera militar y proponía la modificación del edificio de San Benito de Palermo para poder albergar a treinta estudiantes más.

En junio de 1875 las postulaciones provienen en su mayor parte de descendientes de militares o de jóvenes recomendados por sus parientes militares. Hasta ese momento la admisión de postulantes sólo alcanza para superar las bajas que se van produciendo y seguir sosteniendo las cincuenta plazas disponibles. ${ }^{60}$ En julio del mismo año se concreta la idea de Alsina de contar con 80 "aspirantes" a oficiales y se introduce una reforma en el reglamento que modifica las condiciones de ingreso al colegio, el régimen de castigos disciplinarios y los modos en los que los egresados del establecimiento serán incorporados a las unidades militares.

El aumento en el número de aspirantes ${ }^{61}$ pone en evidencia una serie de inconvenientes relacionados con la carencia de condiciones necesarias para una buena instrucción de los reclutas y se registran problemas de convivencia entre las actividades del colegio y los vecinos y trabajadores del Parque 3 de Febrero. ${ }^{62}$ El ministro Alsina personalmente tomará las medidas disciplinarias correspondientes, atribuyendo estos problemas a la falta de adecuación de las instalaciones del colegio que fuera la antigua residencia de Rosas. El establecimiento en aquel momento estaba situado en medio de un lugar de esparcimiento público - el parque 3 de febrero-, "circunstancia que hace más difícil la disciplina, y distrae a los alumnos quitando al estudio y á la reflexión un tiempo precioso". Agregaba Alsina que, como el edificio de Palermo fue construido "para mansión de un tirano extravagante, no llena, en manera alguna, las condiciones requeridas". ${ }^{63}$

59 Carta de Alsina a Mariano Moreno, entonces director del colegio, Reglamento del Colegio Militar con sus modificaciones, p. 31.

${ }^{60}$ En junio de 1875 hay 49 aspirantes en los cuatro cursos de $1^{\circ}$ a $4^{\circ}$ año: 18 en $1^{\circ}, 16$ en $2^{\circ}, 8$ en $3^{\circ}$ y 7 en $4^{\circ}$. Colegio Militar, lista de alumnos de $1^{\circ}$ a $4^{\circ}$ año. EMGE, Organización Nacional, Caja 56, Carpeta 275, documento $16785,1^{\circ}$ de junio de 1875.

61 Entre los nuevos aspirantes, el primero de julio de 1875 ingresa Pablo Ciriaco Riccheri, futuro ministro de guerra, conocido luego por impulsar las leyes y reformas que propiciarían la definitiva profesionalización del Ejército argentino a principios del siglo Xx.

62 Por aquellos días de julio se realizaban obras de remodelación del Parque 3 de febrero y el director del Colegio recibió la denuncia de que sus alumnos habían dañado plantas y faroles, lo que motivó la prohibición a todo el personal y alumnos de internarse en el Parque sin ser acompañados por un oficial designado. Orden del día, Colegio Militar, 14 de enero de 1876.

63 Memoria presentada por el Ministro Secretario de Estado en el Departamento de Guerra y Marina Dr. D. Adolfo Alsina al Congreso Nacional en 1876, Buenos Aires, Imprenta del Porvenir, 1876, pp. 37-38. 


\section{LA POLÍTICA EN LAS AULAS}

La experiencia de los primeros años de existencia del colegio es atravesada por las guerras contra las fuerzas de López Jordán entre 1870 y 1873 y más tarde por las convulsiones políticas de las disputas facciosas y la cuestión electoral durante 1874. En abril de ese año un incidente con motivo de las elecciones presidenciales determina la destitución de Juan Czetz de la dirección del colegio. Según el testimonio del propio Czetz fue dado de baja a partir de una serie de cuestionamientos ocurridos luego de ser sospechado de partidario de la candidatura mitrista. ${ }^{64}$ En su lugar fue designado Mariano Moreno (hijo), quien estará en el cargo hasta $1876 .{ }^{65}$

Desde el año 1873 encontramos diversos incidentes protagonizados por alumnos del colegio y reflejados en sumarios internos que fueron elevados al Ministerio de Guerra. Estos incluyen causas como la deserción, ataques vandálicos a los transeúntes, denuncias de padres de un alumno contra la violencia ejercida por un profesor, un sumario a otros estudiantes que "estropearon gravemente a un compañero", y otro "proceso levantado para esclarecer los grados de culpabilidad de varios aspirantes que eran acusados de entregarse, casi sin reserva, al asqueroso vicio de la sodomía" ${ }^{66}$ tan inaceptable dentro de la institución militar. Las penas aplicadas a esas faltas iban desde la suspensión de recreos, pasando por la sanción de arresto de 24 horas y hasta los 6 meses, o bien, la baja del Ejército y expulsión del colegio. Esta última medida se tomó solo en algunos casos que tomaron estado público a raíz de una polémica que involucraba a dos facciones de estudiantes del colegio enfrentadas a través de los periódicos porteños. ${ }^{67}$ Las sanciones de expulsión

64 Dice Czetz en sus memorias que cuando se gestaba la candidatura de Avellaneda por parte de Sarmiento y Gainza, él asistió a un banquete en honor del Dr. Manuel Quintana, candidato mitrista. A partir de allí, según relata, el ministro Gainza "con la vanidad innata que caracterizaba todos sus actos, lo tomó a lo serio y encontró en el suficiente motivo para provocar bajo cuerda una sublevación o motín entre los cadetes y de formar un sumario cuyo resultado fue la destitución del director". Memorias de Juan Czetz, en García Enciso, Historia del Colegio Militar, p. 324.

65 Está en el cargo hasta abril de 1876, renuncia por motivos de salud, falleciendo en julio del mismo año.

66 EMGE, Servicio Histórico, Organización Nacional, Caja 66, carpeta 313, política interna y causas, sumario contra aspirantes por insubordinación e inobediencia, documento 18520, nota del 12 de abril de 1877.

${ }_{67}$ La disputa que provoco el sumario interno y las posteriores expulsiones se originó al formarse una comisión de alumnos del Colegio Militar encargados de la colecta de fondos para la repatriación de los restos del General San Martín. Una comisión de estudiantes fue designada de manera oficial por el presidente Avellaneda, apareciendo en una serie de solicitadas en diversos diarios. Otro grupo de alumnos publicó el 7 de abril de 1877 una nota en El Porteño, periódico de Héctor Varela, donde se acusaba de usurpadores y falsos patriotas que engañaron al Presidente para reivindicarse como comisión oficial y obtener dinero con 
de la institución acompañada de la prohibición de formar parte del Ejército, dadas a las faltas consideradas más graves, fueron disposiciones cuya decisión final recayó en el presidente Avellaneda, en su rol de Comandante en Jefe. ${ }^{68}$ Este protocolo expresaba el control del ejército y su sometimiento a la autoridad presidencial, una característica que está plasmada en su normativa y que puede apreciarse en el quehacer cotidiano de la institución, como parte de su cultura institucional y apuntando a convertirse en el rasgo distintivo del futuro el oficial formado en el Colegio Militar.

En general se toleraban los actos de indisciplina e insubordinación sin mayores consecuencias cuando los informes sobre la aplicación al estudio y al conocimiento eran satisfactorios. Inversamente, se disimulaba la falta de aptitudes y dedicación al estudio si los informes de conducta no registraban incidentes. Según el director Mariano Moreno los episodios de insubordinación que se registraron al comenzar el año 1875 fueron los coletazos de las convulsiones producidas por la rebelión mitrista. En una carta al Ministro Alsina afirma que las consecuencias del levantamiento militar en la actitud de muchos cadetes fue una relajación de la aplicación al estudio y unos pocos saludables deseos de protagonismo político en los jóvenes que fueron movilizados para reprimir la revuelta. Al estallar la rebelión mitrista se había formado una compañía de escoltas con cadetes del Colegio encargados de custodiar la asunción de Avellaneda el 12 de octubre de 1874. Según el director, esos hechos sirvieron para "distraer a los alumnos de su atención principal, hacerles perder el hábito del estudio y despertar en ellos aspiraciones prematuras, que han traído por consecuencia la separación de muchos de los destinados a servir en comisión en los cuerpos de ejército, eliminándose así, en cada una de las clases, la mayor parte de los alumnos más aventajados" ${ }^{69}$ Debido al estado de agitación producido por la rebelión mitrista se suprimió el egreso de oficiales a fines de 1874. Las referencias transmitidas por las autoridades del colegio y el propio ministro de guerra indican que los jóvenes oficiales adquirían rápidamente la conciencia de pertenecer a una corporación que tiene un papel importante en la disputa política. A esta situación se añadía el prestigio que portaban quienes triunfaban en los campos de batalla, rodeándose de una celebridad guerrera. El director del colegio y el ministro señalaban la mala combinación que resultaba de unir esas aspiraciones con la

fines espurios. Sobre estos últimos recayeron las sanciones.

68 El 19 de abril de 1877 el presidente Avellaneda resuelve " $1^{\circ}$ que los aspirantes Pedro Vilches, Carlos Alais, Pedro Berhá y Carlos Sibiliches sean dados de baja del Colegio Militar con prohibiciones respecto del primero para ingresar en el Ejército de la Nación”. EMGE, Servicio Histórico, Organización Nacional, Caja 66, carpeta 313, política interna y causas, sumario contra aspirantes por insubordinación e inobediencia, documento 18520.

69 Mariano Moreno al Ministro Alsina, 20 de junio de 1875. Historia del Colegio Militar, op. cit., p. 39. 
juventud e inexperiencia de los cadetes. Una mezcla que, desde su perspectiva, desarreglaba el clima propicio para el estudio y provocaba la relajación en la disciplina.

Al comenzar el año 1876, luego de algunas altas de alumnos en el Ejército y con la incorporación de nuevos aspirantes, habría 70 cadetes en todos los cursos del colegio. Durante los primeros diez años de existencia del colegio, entre 1870 y 1880 , egresaron 84 oficiales de sus aulas. La primera promoción de trece oficiales se graduó en 1873; al año siguiente debido a las convulsiones producidas por la guerra contra los mitristas sólo finalizan sus estudios cinco cadetes más, quienes serán incluidos en la promoción de 1875 donde se añaden otros ocho, sumando un total de otros trece oficiales para la segunda promoción. La tercera camada fue de cinco en 1876, la cuarta dio un total de once en 1877, fueron nueve en 1878, dieciocho en 1879 y quince en 1880. Recién en 1884 el número de egresados sobrepasa los treinta y se mantiene en números similares, excepto en 1891, luego de las turbulencias producidas por la revolución del parque. ${ }^{70}$

\section{Ejército viejo y ejército nuevo}

Los primeros egresados incorporados a las unidades del ejército serán bautizados por sus jefes como los "científicos" debido a su procedencia de la academia en la que han aprendido los principios teóricos y los métodos del arte de la guerra. En el desplazamiento desde el instituto militar hacia la práctica aparecía otra realidad, la de las unidades del Ejército de Línea, que solía impresionar a los jóvenes oficiales debido al desfase entre un escenario ideal y otro rodeado de abundantes carencias. Este contraste expresaba José Daza al relatar una sesión de castigo que le tocó presenciar a poco de incorporarse al ejército cuando se aplicó la famosa "carrera de baqueta" a seis desertores del regimiento de caballería en junio de $1874 .^{71}$ La impresión de esos hechos se intensificaba en su sensibilidad, según su relato, debido a la impronta de la formación militar recibida:

...ingrato efecto me causó; tanto más, habiendo sido alférez recién egresado del Colegio Militar, donde se nos había enseñado el derecho de gentes, ó de humanidades, tendiente á mitigar los horrores de las guerras. Allí no existía

70 Figueroa, Promociones Egresadas del Colegio Militar de la Nación, pp. 161-164.

71 Los reos debían atravesar entre dos filas de soldados armados con plantas de varilla. Mientras algunos condenados elegían pasar corriendo entre las filas, otros "caminaban al paso, cual mártir del Gólgota. Tanto los que corrían como los que no, recibieron trescientos varillazos, desgarrándoles los pulmones, salpicando una lluvia de sangre". Daza, Episodios militares, p. 83 . 
ningún enemigo, no se libraba ningún combate; sin embargo, veía correr raudales de sangre y cometer actos reñidos con la cultura nacional. ${ }^{72}$

Poco a poco los cientificos se irán sumando al ejército ocupando puestos subalternos en las comandancias, guarniciones y fortines del desierto y abonando el camino hacia la profesionalización del Ejército. Paralelamente, la experiencia en los campamentos militares seguiría siendo una puerta de acceso a la carrera de oficial con la incorporación directa a las filas como cadetes o distinguidos de muchos soldados que irán ocupando posiciones relevantes. De modo que la formación práctica seguirá coexistiendo con la llegada de oficiales salidos de la academia militar. Al comenzar la década de 1880 ya hace varios años que el Colegio Militar provee a los futuros oficiales del ejército. Será a partir del año 1881 cuando se produzca la eliminación de la figura de los "cadetes" que se formaban en las unidades, siendo reemplazados por los oficiales educados en la academia. ${ }^{73}$ A partir de entonces los nuevos cuadros militares serán exclusivamente de origen "científico" y con el correr de los años irá creciendo el número de jóvenes formados en la institución y esos oficiales ascendiendo posiciones en el escalafón. ${ }^{74}$

A fines del siglo XIX se fue haciendo visible una cierta división entre los componentes del llamado ejército viejo y los del ejército nuevo. Los primeros formados en la dura experiencia de los campamentos de la guerra en el Paraguay o las distintas guerras civiles, y los otros, miembros del ejército nuevo compuesto por los cientificos que pasaron por las aulas del instituto de Palermo. Unos y otros se verán envueltos en las convulsiones políticas de las décadas siguientes agitando una rivalidad que llegó a evidenciarse incluso en el siglo xx durante las discusiones del proyecto de profesionalización del

Ibid., p. 84.

73 El director de El Colegio Militar, Simón A. de Santa Cruz, en carta al ministro Victorica se refiere a un decreto del 24 de septiembre de 1880 que elimina la figura del "cadete" y espera que el próximo paso sea eliminar a los soldados "distinguidos" que se convierten en aspirantes a oficiales en las mismas unidades. Memoria del Ministerio de Guerra y Marina, 1881, pp. 268-269.

74 En 1884, luego de catorce años de funcionamiento del Colegio Militar, todavía existía un alto número de oficiales formados en las unidades de tropa. Por este motivo, durante ese año se constituyó una "Academia Militar" para aquellos oficiales "que carecen de la instrucción científica, tanto teórica como práctica, imprescindible para el servicio y necesidades de una campaña". Fue un curso que duró nueve meses y se desarrolló con 129 inscriptos, imponiéndose como obligatorio para los oficiales de la guarnición Buenos Aires que no hubiesen pasado por las aulas de Palermo. Estaba dirigido por el coronel Juan Czetz (primer director de Colegio Militar) y se dictaron cursos de geografía práctica, dibujo topográfico, fortificación de campaña y geografía militar. Rodríguez, Reseña Histórica y del Ejército Argentino (1862-1930), p. 75. 
ejército en $1901 .^{75}$ En aquellas sesiones todavía podían oírse las voces de algunos oficiales orgullosos de la instrucción militar recibida en los cuarteles y producto de largas campañas militares. Los opositores del proyecto de ley 4031(Ley Riccheri) que establecía la conscripción obligatoria reprocharon al Ministro el ser un oficial de academia que conocía mejor los ejércitos europeos que los de su propio país. Desautorizaban sus conocimientos por considerarlos puramente teóricos, junto con las propuestas de reforma militar dado que, desde su punto de vista, el ministro Riccheri carecía de la experiencia y el criterio práctico que dan los años de servicio efectivo. ${ }^{76}$

\section{Conclusión}

La centralización del poder militar en la nación requería la eliminación del poder de la milicia provincial a través del sometimiento definitivo de la Guardia Nacional a la autoridad de la nación. El Estado nacional es una forma de organización política que se edifica sobre otras formas de autoridad y de gobierno preexistentes, de modo que las normas, prácticas y acciones políticas orientadas a conducir la autoridad hacia el poder central surgen de una interrelación entre los poderes provinciales y los nacionales. ${ }^{77} \mathrm{La}$ reforma militar encarada a comienzos de la década de 1870 estuvo directamente vinculada con el avance del Estado nacional. La efectividad de la puesta en práctica de esas reformas significaría que el Estado nacional estaría representado militarmente por el ejército profesional. La ley de reclutamiento de 1872 planteaba la modificación en las funciones y el modo de reclutamiento de la Guardia Nacional con el propósito de una trasformación hacia el modelo militar de Estado centralizado, diferente al modelo estatal representado por la Guardia nacional.

75 Estas diferencias eran conocidas en el ámbito político de la época y aparecen en la iconografía militar a partir del Roquismo se muestran reflejadas en las apariencias de los oficiales. Los hombres del Ejército Viejo usaban la visera de los quepis hacia arriba y los bigotes hacia abajo, y los del Ejército Nuevo, las viseras hacia abajo y los bigotes hacia arriba.

76 El general Alberto Capdevila exclamaba en el Congreso: "Terminados sus estudios en el Colegio Militar, el Señor Ministro de Guerra se fue a Europa a estudiar y, allí ha estado veinte años (...) ausente de las filas del ejército nacional, sin duda con la información de los colegios y los libros circulantes, pero sin la experiencia ni el criterio de la vida de cuartel y de campaña que tanto enaltece, depura y consolida el juicio del soldado." Capdevila hacía esta valoración, siendo que él también había pasado por las aulas del Colegio Militar, aunque fue dado de alta prematuramente en el Ejército antes de completar sus estudios, durante las guerras contra López Jordán en 1873. Con lo cual su formación inicial se articuló entre la academia y los campos de batalla. Cámara de Diputados de la Nación, Diario de Sesiones, 1, 1901, p. 354.

77 Sabato, "Hacer política en tiempos de república", pp. 35-38. 
Hemos mostrado que, desde la perspectiva oficial, para conseguir el control del ejército y la sumisión a la autoridad presidencial había que formar militares que acataran sin dudar las órdenes del Poder Ejecutivo y éste será el rasgo distintivo de los futuros oficiales formados en el Colegio Militar. El proyecto de Sarmiento de separar al ejército de las luchas facciosas mediante su profesionalización planteaba la naturaleza dual del arte de la guerra. Una ciencia autónoma con sus propios procedimientos, pero a la vez una actividad subordinada en tanto que sus fines provienen del poder político en función de sus propios objetivos. Preparar militares profesionales implicaba separarlos de la disputa política para subordinarlos a la autoridad estatal. La educación en la academia militar aspira a reemplazar las prácticas basadas en relaciones personalistas por un modelo burocrático que prepare oficiales para responder de manera impersonal al Estado nacional. Hemos repasado el funcionamiento del colegio en sus primeros años de existencia y pudimos entrever las formas en que la disputa político-militar se colaba en sus aulas modificando algunos de los protocolos ideados para separar al Ejército de los altercados militares o los enfrentamientos en torno de la competencia electoral. ${ }^{78} \mathrm{El}$ contexto de militarización de la vida política argentina tornaría dificultoso permitir las condiciones de posibilidad ideales para el desarrollo de la ciencia militar. Sin embargo, los avances institucionales, junto con los diversos proyectos y polémicas en torno del papel de las fuerzas militares en el sistema republicano forman parte de la lenta y poco visible transición entre una sociedad dominada por la guerra hacia una Argentina pacificada. ${ }^{79}$ En ese ciclo de mediano plazo, el Colegio Militar de la Nación irá integrando gradualmente a los nuevos oficiales y abonando el camino hacia la profesionalización del Ejército.

\section{Bibliografía}

Barros, Álvaro, Fronteras y territorios federales de las pampas del sur, Buenos Aires, Imprenta, Litografía y Fundición de tipos a vapor, 1872.

78 El egreso de la primera camada de oficiales "científicos" apresurado por la guerra en Entre Ríos en 1873 es una muestra de ello. Como hemos visto, las guerras en torno de las disputas electorales en 1874 y 1880 también tuvieron sus repercusiones en la academia militar.

79 Sobre el sentido asociado con esta idea de pacificación, véase: Rabinovich, Alejandro y Zubizarreta, Ignacio, "De la guerra a la construcción de la paz (Buenos Aires post caseros)". Los autores proponen en este ensayo "sentar las bases para el estudio de la muy lenta, dificultosa y muchas veces contradictoria transición entre un Río de la Plata dominado por la guerra desde por lo menos 1806, y una Argentina que se presenta al mundo como pacificada hacia 1880". El estudio se concentra en la década que va de Caseros a Pavón, donde se formulan "varios de los mecanismos principales que terminaran permitiendo ese funcionamiento relativamente pacífico de la sociedad", pp. 141-142. 
Botana, Natalio R., La tradición republicana. Alberdi, Sarmiento y las ideas políticas de su tiempo, Buenos Aires, Sudamericana, 1984.

Bragoni, Beatriz y Eduardo Míguez, Un nuevo orden político. Provincias y Estado Nacional, 1852-1880, Buenos Aires, Biblos, 2010.

Canciani, Leonardo, "Las Guardias Nacionales en Argentina durante la organización nacional: balance y perspectivas historiográficas", Historia Unisinos, vol. 16, núm. 3, setembro-dezembro, 2012, pp. 1-12.

https://doi.org/10.4013/htu.2012.163.11

Canciani, Leonardo, "Resistencias a la obligación de armarse. Reclutamiento y servicio militar en la Guardia Nacional de frontera", Memoria americana, Buenos Aires, Cuadernos de Etnografía, vol. 22, núm. 1, 2014, pp. 33-63.

Clausewitz, Carl Von, De la guerra, Buenos Aires, Círculo Militar, 4 tomos, 1970.

Codesido, Lucas, “Zacarías segura, 'Salteador y Montonero'. El caso 'Segura': Justicia militar versus justicia civil en la segunda mitad del siglo XIX. Polémicas en la Cámara de Senadores y la prensa en junio de 1869 por los alcances del fuero militar, luego de la ejecución del ciudadano Zacarías Segura, condenado por un tribunal militar", Cuadernos de Marte, Buenos Aires, año 2, núm. 3, julio, 2012, pp. 223-248.

, "Armar al Estado, construir la Nación. La nacionalización de las fuerzas armadas en la Argentina y su vinculación con el proceso de construcción del Estado nacional", La Plata, 2016. Tesis de Doctorado en Historia. Fahce/UnlP. Disponible en: http://sedici.unlp.edu.ar/handle/10915/62050

Cucchi, Laura y Dapelo, Luciano, "La política en las provincias durante la emergencia y consolidación del Partido Autonomista Nacional", Coordenadas, Revista de Historia Local y Regional, vol. 3, 2016, pp. 84-93.

Cucchi, Laura, "Estado, política y cuestión militar entre 1880 y 1890 . El Partido Autonomista Nacional y la organización de un nuevo Ejército de la Nación", Boletín del Instituto de Historia Argentina y Americana "Dr. Emilio Ravignani", núm. 54, enero-junio, 2021, pp. 58-85.

https://doi.org/10.34096/bol.rav.n54.9529

Daza, José, Episodios Militares, Buenos Aires, Librería La Facultad, 1914.

De Marco, Miguel Ángel, "De la Marina 'fluvial' a la Marina 'atlántica", Oscar Moreno (Coord.), La construcción de la Argentina. El rol de las fuerzas armadas, Buenos Aires, Presidencia de la Nación: Ministerio de Defensa, 2010, pp. 177-188.

Figueroa, Coronel (R) Abelardo Martín, Promociones Egresadas del Colegio Militar de la Nación, Buenos Aires, Edivern, 2001.

Fotheringham, Ignacio, La vida de un soldado, Reminiscencias de las fronteras, Ciudad Argentina, Buenos Aires, 1999.

Foucault, Michel, Microfisica del poder, Madrid, La Piqueta, Tercera edición, 1992. -, Genealogía del racismo, Buenos Aires, Caronte Ensayos, 1996.

Garavaglia, Juan Carlos, "Fuerzas de Guerra y construcción estatal: de la Confederación a la Nación Argentina (1856-1865)", Garavaglia, Juan Carlos; Pro Ruíz, Juan y Zimmermann, Eduardo (editores), Las fuerzas de guerra en la construcción del Estado. América Latina, siglo XIX, Rosario, Prohistoria, 2012, pp. 413-456. 
Garavaglia, Juan Carlos y Fradkin, Raúl, A 150 años de la Guerra de la Triple Alianza contra el Paraguay, Buenos Aires, Prometeo, 2016.

García Enciso, Isaías José, Historia del Colegio Militar de la Nación, Buenos Aires, edición en su centenario, 1969.

García Molina, Fernando, La prehistoria del poder militar en la Argentina. La profesionalización, el modelo alemán y la decadencia del régimen oligárquico, Buenos Aires, Eudeba, 2010.

Lanteri, Ana Laura, "(Inter) acciones para un nuevo orden nacional. La experiencia política de San Juan a partir de la Circunscripción Militar del Oeste y el Congreso durante la 'Confederación' (1855-1858)", Anuario Del Instituto De Historia Argentina, núm. 14, 2014, pp. 1-21.

Literas, Luciano, Vecindarios en armas. Sociedad, Estado y milicias en las fronteras de Pampa y Norpatagonia (segunda mitad del siglo XIX), Rosario, Prohistoria, 2017.

Macías, Flavia, "Las fuerzas militares entre la provincia y la nación (1868-1874)", en Dossier: Las milicias en acción, Historia política, 2011. http://historiapolitica.com/dossiers/dossiermilicias/. , "El deber de enrolarse y el derecho a votar. Reflexiones en torno a la ciudadanía armada y el sufragio en argentina, 1863-1877”, Revista de Indias, vol. LXXVI, núm. 266, 2016, pp. 233-258. https://doi.org/10.3989/revindias.2016.008 , “Orden y violencia política. Argentina, 1870-1880”, Pasado Abierto, núm. 7, 2018, pp. 227-240.

Macías, Flavia y Sabato, Hilda, "La Guardia Nacional: Estado, política y uso de la fuerza en la Argentina de la segunda mitad del siglo xix", PolHis, año 6, núm. 11,2013 , pp. $70-81$.

Macías, Flavia y Navajas, María José, "De los comicios al campo de batalla (1874)", Sabato, Hilda y Ternavasio, Marcela (Coords.), Variaciones de la república. La política en la Argentina del siglo XIX, Rosario, Prohistoria, 2020, pp. 159-180.

Mendizábal, Ernesto, Historia de un crimen, Buenos Aires, Pablo E. Coni, 1881.

Oszlak, Oscar, La formación del Estado argentino, Buenos Aires, Editorial de Belgrano, 1982.

Pomer, León, La guerra del Paraguay Gran Negocio!, Buenos Aires, Caldén, 1968.

Prado, Manuel, La guerra al malón, Buenos Aires, Biblioteca Clásica Americana, 1942.

Quinterno, Hugo, Fuego amigo. El Ejército y el poder presidencial en la Argentina. 1880-1912, Buenos Aires, UAI-Teseo, 2014.

Rabinovich, Alejandro y Zubizarreta, Ignacio, "De la guerra a la construcción de la paz (Buenos Aires post caseros)". Sabato, Hilda y Ternavasio, Marcela (Coords.), Variaciones de la república. La política en la Argentina del siglo XIX, Rosario, Prohistoria, 2020, pp. 139-157.

Ratto, Silvia, "El frustrado proyecto de avance territorial del Estado Nacional entre 1869-1872”, Memoria Americana, vol. 19, 2011, pp. 93-119. , "Estado y cuestión indígena en las fronteras de Chaco y La Pampa (18621880)", Revista de Ciencias Sociales, segunda época. Dossier: Estado y pueblos indígenas en Latinoamérica, Unqui, año 3, núm. 20, Bernal, 2011, pp. 7-28. 
Rodríguez, Augusto, Reseña Histórica del Ejército Argentino (1862-1930), Buenos Aires, Secretaría de Guerra, Dirección de Asuntos Históricos, 1964.

Sabato, Hilda, Buenos Aires en armas. La revolución de 1880, Buenos Aires, Siglo XXI, 2008.

, "Resistir la imposición: revolución, ciudadanía y república en la Argentina de 1880", Revista de Indias, vol. LXIX, núm. 246, 2009, pp. 159-182. https://doi. org/10.3989/revindias.2009.016

- "Hacer política en tiempos de república", Sabato, Hilda y Ternavasio, Marcela (Coord.), Variaciones de la república. La política en la Argentina del siglo XIX, Rosario, Prohistoria ediciones, 2020, pp. 19-38.

Sarmiento, Domingo Faustino, Obras Completas, Papeles del Presidente, (1868-1874), segundo volumen, Universidad Nacional de la Matanza, La Matanza, 2001.

Scenna, Miguel, Los militares, Buenos Aires, Editorial de Belgrano, 1980.

Sewell, William, "The Concept(s) of Culture", Victoria Bonnell y Lynn Hunt (Comps.), Beyond the Cultural Turn, Berkeley, University of California, 1999, pp. 35-61.

Sillitti, Nicolás, "El levantamiento armado de 1905. Estado, Ejército y delito político en la Argentina a comienzos del siglo xx", Tesis de Maestría en Investigación Histórica, Buenos Aires, Universidad de San Andrés, 2014.

Tilly, Charles, Coerción, capital y los Estados europeos 990-1990, Buenos Aires, Alianza Editorial, 1993.

Zimmermann, Eduardo, "En tiempos de rebelión. La justicia federal frente a los levantamientos provinciales, 1860-1880". Beatriz Bragoni y Eduardo Míguez (Coords.), Un nuevo orden político. Provincias y estado nacional, 1852-1880, Buenos Aires, Biblos, 2010, pp. 245-274.

, "Guerra, fuerzas militares y construcción estatal en el Río de la Plata, siglo xIx. Un comentario", Garavaglia, Pro Ruíz y Zimmermann (Eds.), Las fuerzas de guerra en la construcción del Estado. América Latina, siglo XIX, Rosario, Prohistoria, 2012, pp. 185-204. 